
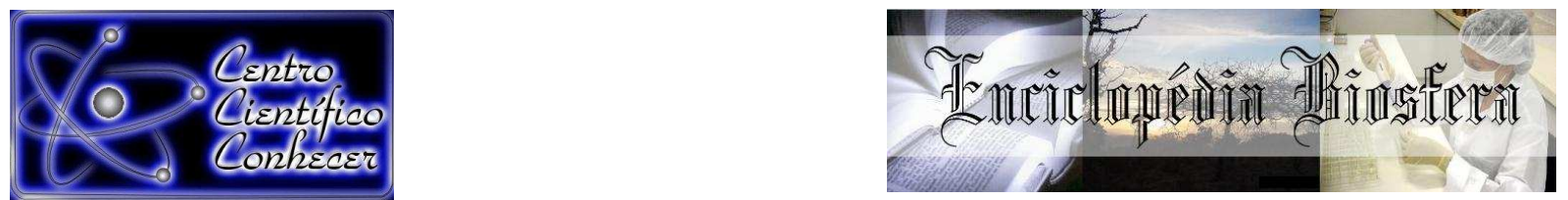

\title{
EFEITOS DA APLICAÇÃO DA VINHAÇA EM CAPIM ARUANA (Panicum maximum JACQ. CV. ARUANA)
}

Simone Costa de Oliveira ${ }^{1}$, Liliane Scabora Mioto², Maiara Kawana Aparecida Rezende $^{3}$, Altair Bertonha ${ }^{4}$, Paulo Sérgio Lourenço de Freitas ${ }^{5}$

1. Engenheira Agrícola, Universidade Estadual de Maringá, Teodoro Sampaio -

Brasil. Email: simonengenhariagricola@gmail.com

2. Mestranda em agronomia, Universidade Estadual de Maringá, Maringá - Brasil.

3. Mestranda em agronomia, Universidade Estadual de Maringá, Maringá - Brasil.

4. Professor Doutor do Curso de Agronomia, Universidade Estadual de Maringá, Maringá - Brasil

5. Professor Doutor do Curso de Agronomia, Universidade Estadual de Maringá, Maringá - Brasil.

Recebido em: 08/09/2015 - Aprovado em: 14/11/2015 - Publicado em: 01/12/2015 DOI: http://dx.doi.org/10.18677/Enciclopedia_Biosfera_2015_146

\section{RESUMO}

A vinhaça gerada na produção do etanol apresenta em sua composição água, matéria orgânica e elementos químicos que são importantes, tanto para a fertilidade do solo, quanto para o desenvolvimento das plantas, tornando este resíduo de grande importância para reuso como fonte de água e fertilizante na agricultura. Por não apresentar contaminação de agentes patogênicos, pode ser aplicado sobre a rebrota de pastagens de pastoreio, visando aumentar seu vigor e a produção de matéria seca. O experimento foi desenvolvido com o objetivo de avaliar a produção de matéria seca e o acúmulo de nutrientes na parte aérea durante um ciclo de produção do capim Aruana, cultivado em um Latossolo vermelho distrófico, fertirrigado com vinhaça. Os tratamentos com vinhaça foram definidos ao longo do raio molhado de um aspersor com lâminas totais de $0,10,30,38,76$ e $110 \mathrm{~mm}$. A vinhaça foi aplicada durante os primeiros vinte e oito dias sobre o capim, que apresentou um ciclo de 70 dias, quando este foi cortado. Observou-se que o capim Aruana obteve uma produção máxima de $8,00 \mathrm{mg} \mathrm{ha}^{-1}$ para uma lâmina ótima de $44,38 \mathrm{~mm}$. A aplicação de vinhaça aumentou a quantidade de cálcio e potássio, não apresentando significância dos níveis de nitrogênio e magnésio e houve redução nos teores de fósforo e enxofre acumulado na parte aérea da cultura.

PALAVRAS-CHAVE: Acúmulo de nutrientes, matéria seca, reuso.

\section{THE EFFECT OF VINASSE APPLICATION ON ARUANA GRASS (PANICUM MAXIMUMJACQ. CV. ARUANA)}

\footnotetext{
ABSTRACT

The vinasse from the production of ethanol for water in its composition, organic matter and chemicals that are important both for the fertility of the soil as well as for plant

ENCICLOPÉDIA BIOSFERA, Centro Científico Conhecer - Goiânia, v.11 n.22; p.1096 2015
} 
growth, making this extremely important residue for reuse as a source of water and fertilizer in agriculture. Why not introduce contamination of pathogens, can be applied to the regrowth of pasture grazing, to increase their vigor and dry matter production. The experiment was carried out to evaluate the production of dry matter and nutrient accumulation in shoots during a production cycle of Aruana grass grown in an Oxisol fertirrigated with vinasse. The treatments of vinasse are set along the radius of wet rotor blades with total $0,10,30,38,76$ and $110 \mathrm{~mm}$. The vinasse was applied during the first twenty-eight days on the grass which had a cycle of 70 days, when it was cut. It was observed that the grass Aruana obtained a maximum production of $8.00 \mathrm{mg} \mathrm{ha}^{-1}$ for a blade of great $44,38 \mathrm{~mm}$. The application of vinasse increased the amount of calcium and potassium, showing no significant levels of nitrogen and magnesium and lowered levels phosphorus and sulfur accumulated in shoots of this plant.

KEYWORDS: Accumulation of nutrients, dry matter, reuse.

\section{INTRODUÇÃO}

Atualmente uma das alternativas para minimizar problemas ambientais, acarretados pelo lançamento de águas residuárias em cursos d'água, é o uso da mesma na agricultura, além de beneficiar o incremento na produtividade agrícola (SOUZA et al., 2010; KUMMER et al., 2012). A disposição de águas residuárias no solo consiste no fornecimento de água e nutrientes para o sistema solo-planta, os quais contribuem para o melhor desenvolvimento e produtividade das plantas (FONSECA, 2001).

Dentre as inúmeras águas residuárias aplicadas no solo, a vinhaça se destaca, sendo o principal efluente proveniente das agroindústrias sucroalcooleiras (MATOS et al., 2013 a). A vinhaça é o resíduo gerado do beneficiamento da cana de açúcar, possui alto poder poluidor, sendo gerada em grande quantidade, dado que a cada $1 \mathrm{~L}$ de álcool produzido, em média, 13 litros de vinhaça são produzidos (PAULINO et al., 2011).

Considerado um problema para muitos, a vinhaça de acordo com BASSO et al. (2013) é rica em potássio e sua aplicação ao solo pode aumentar a disponibilidade de nutrientes e incrementar a produção das culturas. Os autores estudaram a adição de vinhaça ao solo como fonte de potássio na sucessão aveia preta/milho, silagem/milho safrinha e verificaram que esse resíduo pode ser usado em substituição a adubação mineral com cloreto de potássio. Em estudo ZOLIN et al. (2011) constataram acréscimos de macronutrientes como $\mathrm{K}, \mathrm{Ca}$ e $\mathrm{Mg}$ após uso de vinhaça como fonte de adubação para cultura da cana-de-açúcar, sem que tenha acontecido indisponibilidade dos demais nutrientes do solo. SILVA et al. (2014) argumentam que os óxidos de cálcio e de magnésio presente na composição da vinhaça pode atuar como corretivos do solo. A vinhaça adiciona alguns elementos químicos no solo, tais como $\mathrm{Ca}, \mathrm{Mg}$ e $\mathrm{K}$ existindo um efeito de diluição de $\mathrm{H}^{+}$na solução do solo, contribuindo para a elevação do pH. SILVA et al. (2013) observaram que a aplicação de vinhaça ocasionou efeito significativo nos parâmetros relacionados ao desenvolvimento vegetativo da pastagem. MARTINS et al. (2013) verificaram que as diferentes doses de vinhaça aplicadas na cultura do milho, promoveram alterações significativas nos parâmetros vegetativos analisados (altura de plantas, diâmetro de caule, massa fresca da parte aérea, massa fresca da raiz, massa seca da parte aérea e massa seca da raiz). 
O lançamento da vinhaça ao solo na cultura da cana-de-açúcar é uma prática comum no Brasil, no entanto sua utilização como fonte de água e nutrientes para outras culturas é atividade mais recente. A aplicação da vinhaça em pastagem vem atraindo pesquisadores, em virtude dos benefícios, tais como: nutrientes, água e alternativa de descarte, em razão das leis ambientais não permitirem efetuar o descarte do mesmo em corpos hídricos, devido seu alto poder de poluição (SILVA et al., 2013). Entretanto apesar de seu efeito benéfico, é necessário que se tenha conhecimento da dose apropriada de vinhaça a ser aplicada no solo, pois o excesso pode acarretar alterações nos atributos químicos do solo. Conforme SILVA et al. (2014) a vinhaça possui baixo pH e elevada demanda química de oxigênio (DQO), ou seja, alta carga de matéria orgânica contida no efluente, tornando-se um material altamente poluidor.

O Panicum maximum Jacq. cv. Aruana é um capim cespitoso de porte médio, alcançando $0,80 \mathrm{~cm}$ de altura e apresenta panículas como inflorescência. $O$ capim Aruana enquadra-se na faixa dos capins mais exigentes e podem ser cultivados em áreas com precipitação acima de $900 \mathrm{~mm}$ e em solos que apresentam um índice de saturação por base acima de $60 \%$ e $10 \mathrm{mg} \mathrm{dm}^{-3}$ de $P$, produzindo entre 15 e 26 toneladas de MS/ha/ano (FARIA, 2007). Diante do exposto o presente trabalho teve como objetivo avaliar os efeitos da aplicação de vinhaça sobre a produção de matéria seca e acúmulo de nutrientes na parte aérea do capim Aruana.

\section{MATERIAL E MÉTODOS}

O presente trabalho foi conduzido na área experimental do Câmpus do Arenito, da Universidade Estadual de Maringá, localizada na Rodovia PR 482, km 45, município de Cidade Gaúcha - PR, localizado a 23 $22^{\prime} 30^{\prime \prime}$ de latitude sul e 52 $56^{\prime}$ '00" de longitude oeste, com $375 \mathrm{~m}$ de altitude, em uma área cultivada com pastagem de capim Aruana (Panicum maximum Jacq. cv. Aruana) cortada a uma altura de $3 \mathrm{~cm}$. $\mathrm{O}$ clima do local é Sub-Tropical Úmido Mesotérmico, conforme classificação de Köppen. $O$ solo é classificado como Latossolo Vermelho distrófico, originado do arenito Caiuá, com $830 \mathrm{~g} \mathrm{~kg}^{-1}$ de areia, $10 \mathrm{~g} \mathrm{~kg}^{-1}$ de silte e $160 \mathrm{~g} \mathrm{~kg}^{-1}$ de argila (CABRAL et al., 2011).

O trabalho teve início em 22 de dezembro de 2009 quando foi realizada a primeira aplicação de vinhaça, seguida de mais sete aplicações distribuídas duas vezes por semana, durante o período de quatro semanas. Ao término das aplicações de vinhaça, o que totalizou 28 dias, o capim permaneceu 48 dias sem irrigação, quando então foi cortado para análise. Realizou-se uma amostragem de solo, no início do experimento a 0,20 m de profundidade com um trado Holandês em seis pontos da área experimental de forma aleatória, com os quais se compôs uma amostra que foi enviada para análise (Tabela 1).

TABELA 1. Caracterização química do solo da área experimental.

\begin{tabular}{|c|c|c|c|c|c|c|c|c|c|c|}
\hline $\mathrm{pH}$ & & $\mathrm{Al}$ & $\mathrm{H}^{+}+\mathrm{Al}^{3+}$ & $\mathrm{Ca}^{2+}$ & $\mathrm{Mg}^{2+}$ & $\mathrm{K}^{+}$ & SB & CTC & $\mathrm{P}$ & $\mathrm{SSO}_{4}^{2-}$ \\
\hline $\mathrm{CaCl}_{2}$ & $\mathrm{H}_{2} \mathrm{O}$ & & & \multicolumn{4}{|c|}{$\mathrm{cmol}_{\mathrm{C}} \mathrm{dm}^{-3}$} & \multicolumn{3}{|c|}{$\mathrm{mg} \mathrm{dm}^{-3}$} \\
\hline 5 & 5,42 & 0 & 3,17 & 1,92 & 0,57 & 0,08 & 2,57 & 5,74 & 25,6 & 5,42 \\
\hline
\end{tabular}

A aplicação de vinhaça foi realizada com um aspersor, marca Agropolo, modelo NY 30 ER. Com este sistema foram realizadas oito aplicações, a pressão de 
serviço de $1,0 \mathrm{kgf} \mathrm{cm}^{-2}$. A partir do aspersor foram locados três raios molhados, afastados $45^{\circ}$ entre si. Em cada raio molhado foram locadas as parcelas, com $1 \mathrm{~m}^{2}$ de área, distantes dois metros entre si a partir do aspersor.

Em cada parcela foi instalado um pluviômetro a $0,10 \mathrm{~m}$ de altura do solo, onde foram medidas as lâminas aplicadas em cada irrigação (Figura 1). Ao final do experimento o total de vinhaça coletada em cada pluviômetro foi 10; 30; 38; 76 e 110 $\mathrm{mm}$ respectivamente para os tratamentos $\mathrm{T} 1, \mathrm{~T} 2, \mathrm{~T} 3, \mathrm{~T} 4$ e T5. Fora do alcance do jato do aspersor locado exatamente a $14 \mathrm{~m}$ de distância foram demarcadas as parcelas testemunhas (T0), que não receberam vinhaça. $\mathrm{O}$ experimento foi arranjado em delineamento inteiramente casualizado (DIC), com 5 tratamentos e 3 repetições.

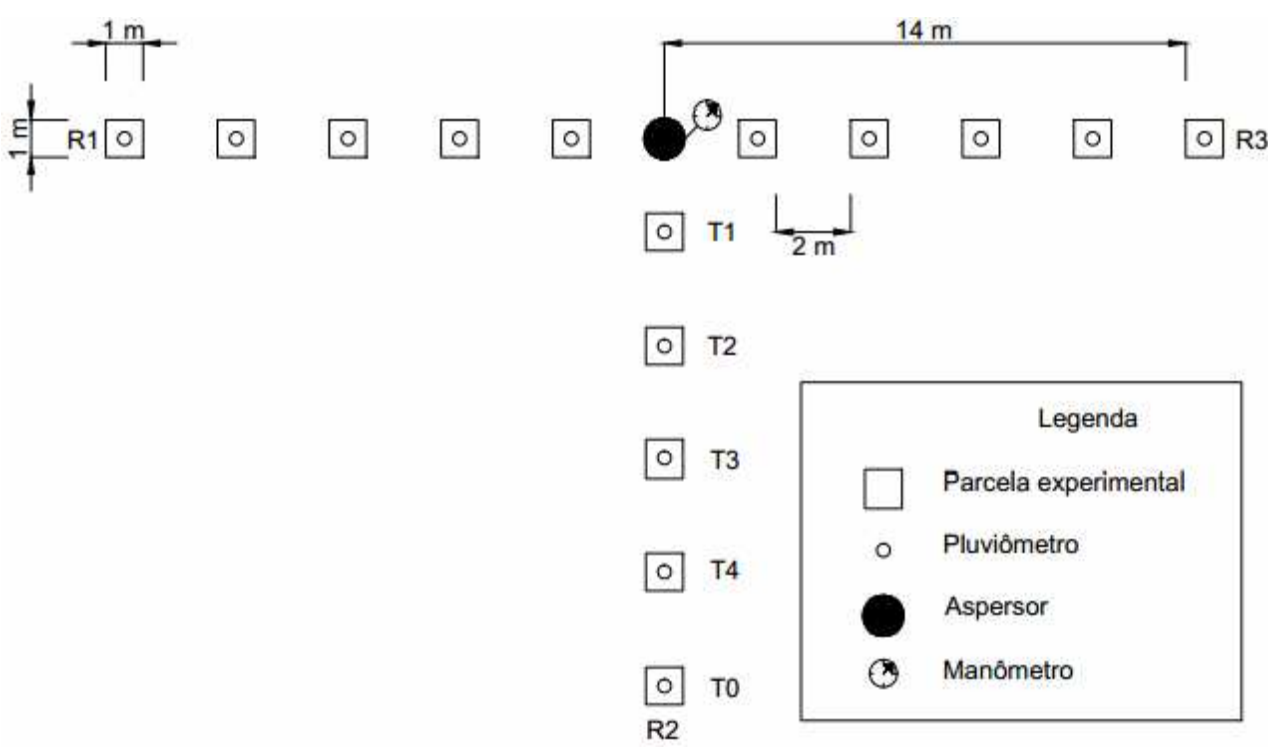

FIGURA 1. Croqui da disposição dos componentes de irrigação na área experimental.

Aos 70 dias após a montagem do experimento, efetuou-se a coleta de toda a massa verde das 15 parcelas de capim para avaliação da matéria seca, análise química e determinação da concentração de nitrogênio $(\mathrm{N})$, cálcio $(\mathrm{Ca})$, magnésio $(\mathrm{Mg})$, fósforo $(\mathrm{P})$, potássio $(\mathrm{K})$ e enxofre $(\mathrm{S})$ do tecido vegetal. A vinhaça utilizada no experimento, cuja composição química encontra-se na Tabela 2, foi coletada na primeira lagoa da Usina Usaciga-açúcar, Álcool e Energia Elétrica Ltda unidade de Cidade Gaúcha, que está localizada na Rod Pr 82, s/n km 14, Cidade Gaúcha-Pr.

TABELA 2. Composição química média da vinhaça.

\begin{tabular}{clllllll}
\hline $\mathrm{C}$ & $\mathrm{MO}$ & $\mathrm{N}$ & $\mathrm{CaO}$ & $\mathrm{MgO}$ & $\mathrm{KO}_{2}$ & $\mathrm{P}_{2} \mathrm{O}_{5}$ & $\mathrm{pH}$ \\
\hline \multicolumn{7}{c}{} \\
\hline 5064 & 9217,93 & 308 & 191 & 201,9 & 1474 & 26,97 & 5,40 \\
\hline
\end{tabular}

Metodologia utilizada nas análise químicas: N (nitrogênio orgânico) - método de Kjeldahl; C (carbono) método titulométrico; $\mathrm{pH}$ - pHmetro na amostra in natura; metais - espectrometria de absorção atômica. 
Os resultados foram submetidos a análises de regressão entre as variáveis independentes com as demais variáveis dependentes, buscando se o modelo que melhor expressasse esta relação, para o qual se utilizou o sistema de análise estatística SAEG (UFV, 1997).

\section{RESULTADOS E DISCUSSÃO}

A relação entre produção de matéria seca e lâmina total de vinhaça aplicada está apresenta na figura 2. Ajustou-se uma equação de regressão de segunda ordem com os dados de produção de matéria seca de capim Aruana (MS) em função das lâminas de vinhaça aplicadas, $y=-0,00008 x^{2}+0,0071 x+0,6433\left(R^{2}=0,60\right)$, com $p \leq 0,01$ pelo teste $\mathrm{F}$ e para os termos da equação pelo teste $\mathrm{T}$.

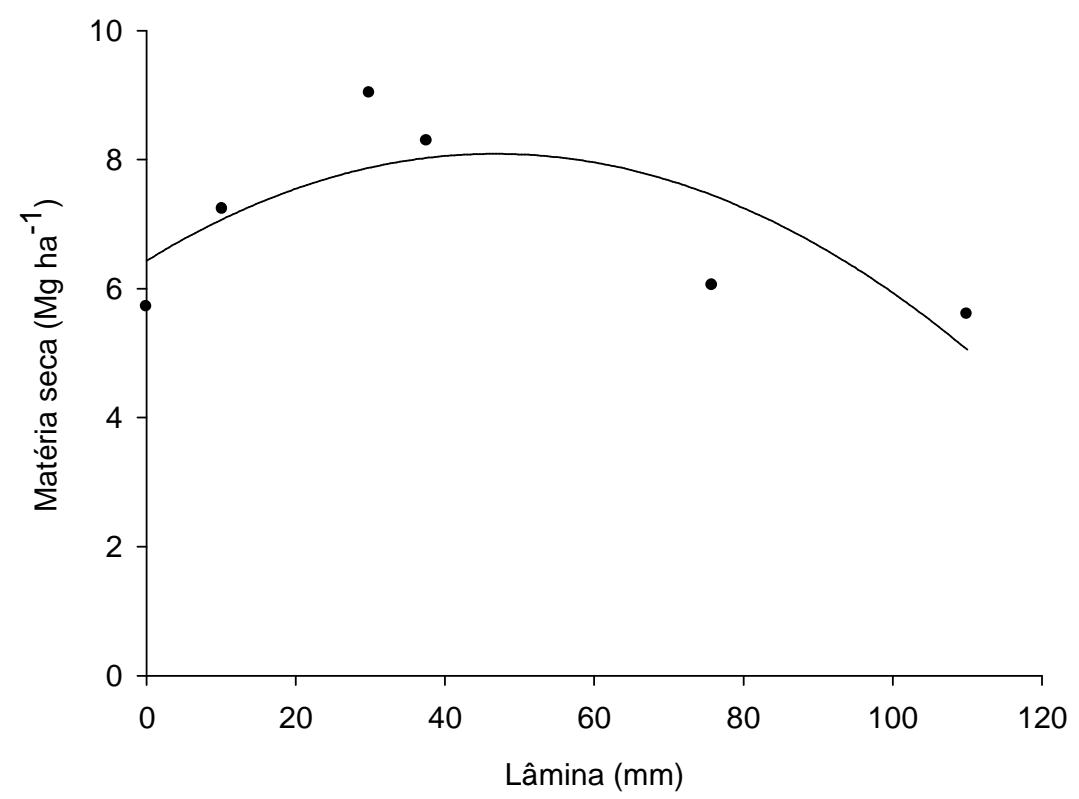

FIGURA 2. Relação entre produção de matéria seca (MS) e lâmina total de vinhaça aplicada.

A produção máxima de MS estimada foi de $0,800 \mathrm{~g} \mathrm{~m}^{-2}\left(8,00 \mathrm{mg} \mathrm{ha}^{-1}\right)$ para uma lâmina ótima de $44,38 \mathrm{~mm}$, valor $19,7 \%$ maior que a produção da testemunha, que foi de $0,643 \mathrm{~g} \mathrm{~m}^{-2}\left(6,43 \mathrm{mg} \mathrm{ha}^{-1}\right)$. Esta variação de produção revela a importância da fertirrigação sobre o capim Aruana com vinhaça, corroborando com os dados de SILVA et al. (2013) que em estudo com aplicação de vinhaça constataram tanto no período chuvoso quanto no seco efeito significativo nos parâmetros relacionados ao desenvolvimento vegetativo de pastagem.. Já no trabalho de BASSO et al. (2013) que ao pesquisarem a resposta da sucessão aveia-preta/milho-silagem/milho mediante a aplicação de vinhaça como fonte de potássio, observaram que a matéria seca da aveia preta, apresentou maior produtividade com a utilização de $100 \mathrm{~m}^{3}$ ha ${ }^{-1}$ de vinhaça. SILVA et al. (2012) verificaram que a produtividade do capim Mombaça aumentou com as doses de efluente de tratamento primário de esgoto sanitário aplicadas e com a idade de corte. Já CABRAL et al. (2011) em estudo com doses de água residuária de suinocultura em capim Elefante não observaram alteração significativa em relação à 
altura das plantas, massa verde e massa seca, entre as diferentes doses e o tratamento que recebeu apenas água de abastecimento.

Os ajustes de absorção de potássio, cálcio e magnésio em $\mathrm{g} \mathrm{kg}^{-1}$ de $\mathrm{MS}$ do capim Aruana em função das lâminas de vinhaça aplicadas estão apresentados na figura 3.. As equações ajustadas foram $y=0,0003 x^{2}-0,0042 x+9,0593\left(R^{2}=0,8941\right)$ e $y=-0,0008 x^{2}+0,0899 x+4,6673\left(R^{2}=0,8322\right)$ sendo $Y$ a quantidade absorvida estimada e X a lamina de vinhaça, respectivamente para a absorção de $\mathrm{K}$ e Ca com $\mathrm{p} \leq$ 0,01 pelo teste $F$ e para os termos da equação pelo teste $T$. $O$ ajuste de absorção de Mg em função das lâminas de vinhaça aplicadas não foi significativo para $p \leq 0,01$ pelo teste $\mathrm{F}$, no entanto a pastagem absorveu $3,8 \mathrm{~g} \mathrm{Kg}^{-1}$ de $\mathrm{Mg}$.

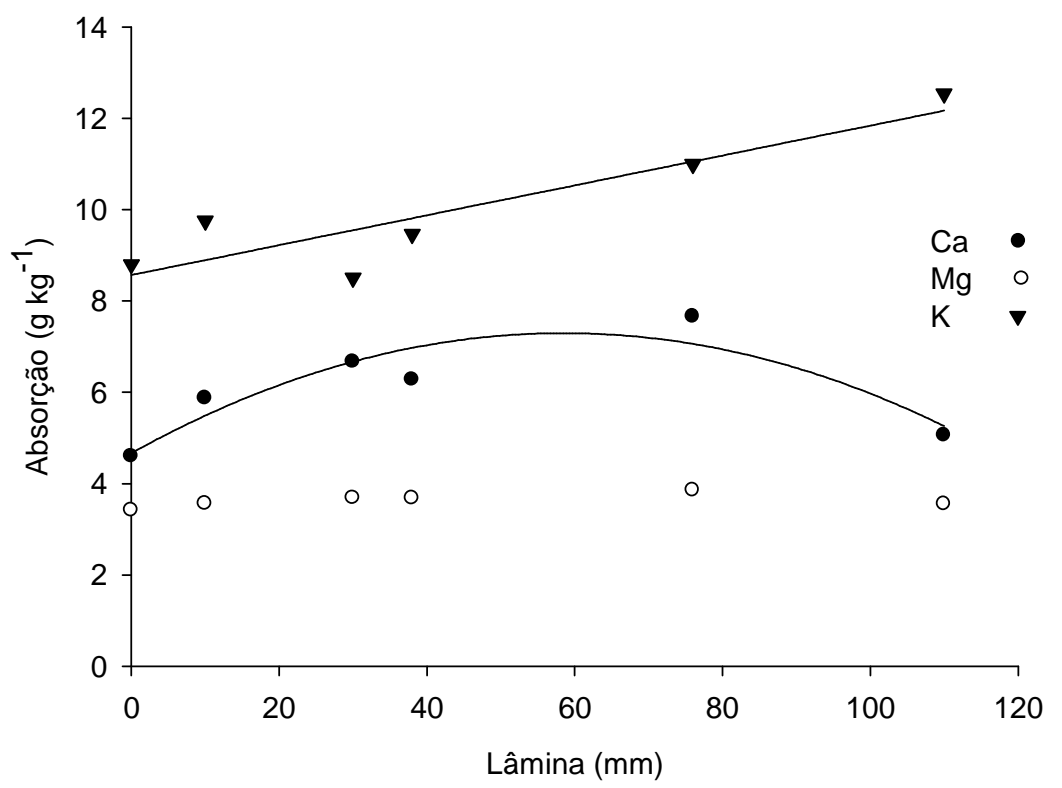

FIGURA 3. Absorção de Potássio, Cálcio e Magnésio pela planta em função da lâmina total de vinhaça aplicada no período experimental.

A quantidade estimada de $\mathrm{K}$ absorvida pela planta variou entre 9,045 e 12,88 $\mathrm{g} \mathrm{Kg}^{-1}$, no entanto a absorção estimada por área, foi respectivamente 58,19 e 103,17 $\mathrm{mg} \mathrm{ha}^{-1}$ para o tratamento testemunha e para a maior produção de MS, ficando abaixo da capacidade de absorção de outras gramíneas, como o milheto Pennisetum glaucum (L.) R. Br. e o Panicum maximum Jacq vr. Mombaça, que segundo BRAZ et al. (2004), absorvem, em condições de culturas não irrigadas, 314 e $164 \mathrm{Kg} \mathrm{ha}^{-1}$, respectivamente.

Em estudo de aplicação de Efluente de Tratamento Primário de Esgoto Doméstico (ETPES) em capim-Mombaça, SILVA et al. (2012) notaram que o capim não sofreu alterações significativas nas concentrações de fósforo, cálcio e magnésio quando comparado ao cultivado sem a aplicação do ETPES, já o teor de potássio, à exceção do T4 (120 litros de EPTES) e T1(30 litros de ETPES e 90 litros de água do poço), obtido respectivamente no segundo e terceiro cortes também não diferiu de T0 (aplicação de água de poço). MATOS et al. (2013 b) em estudo com capim Tifton 85 , verificaram que as plantas que receberam 0 percolado de resíduo sólido urbano apresentaram 
concentrações de potássio nas folhas que foram superiores às obtidas naquelas que receberam água da rede de abastecimento.

BASSO et al. (2013) ao adicionarem vinhaça ao solo como fonte de potássio na sucessão aveia preta/milho, silagem/milho safrinha constataram que com a aplicação de 100 e 200 metros cúbicos por hectare de vinhaça houve acréscimo de 3,1 e 6,9\% no teor de K no solo.. Já PAULINO et al. (2011) observaram o comportamento do solo com adição anual de vinhaça, durante o período 1 até 20 anos e perceberam maiores concentrações de $\mathrm{K}$ quando comparado com áreas sem aplicação.

$\mathrm{O}$ baixo teor de $\mathrm{K}$ observado na análise de solo pode estar relacionado ao seu material de origem e grau de intemperismo, de modo diferente tem-se a vinhaça com elevado teor de K. O potássio é o segundo nutriente em exigência pelas plantas e possui alta mobilidade, assim como pode ser observado na Figura 3, conforme o aumento da aplicação de vinhaça elevou-se a produção de matéria seca do capim Aruana.

A absorção máxima de cálcio, estimada pela equação de regressão foi de $7,19 \mathrm{~g} \mathrm{Kg}^{-1}$ e ocorreu com a aplicação de $56,1 \mathrm{~mm}$ de vinhaça sendo $35,1 \%$ maior que a absorção estimada da testemunha que foi de $4,67 \mathrm{~g} \mathrm{~kg}^{-1}$. Estes valores foram superiores aos observados por CECATO et al. (2001) que verificaram concentração média delcálcio nas lâminas foliares de capim Aruana entre 4,1 a 5,4 g kg-1, em cultivo de sequeiro. Comparando estes valores com os encontrados em outros capins, destacam-se as concentrações máximas de cálcio nas lâminas de folhas recémexpandidas de capim Panicum maximum Jacq vr. Tanzânia $6,4 \mathrm{~g} \mathrm{~kg}^{-1}$ aos 26 dias de rebrota no verão e de 4,1 a $6,4 \mathrm{~g} \mathrm{~kg}^{-1}$ para a rebrota no ciclo de outono (SANTOS Jr., 2005).

A exigência de Ca pelas culturas varia, tomando como conhecimento que o teor de Ca nas plantas varia de 0,1 a $5,0 \%$ do peso é possível verificar que quantidade no capim Aruana está em uma faixa adequada representando 0,719\%. Verifica-se também que depois de um ponto de máxima a produção tem um decréscimo nas maiores lâminas de vinhaça aplicada, isso pode estar relacionado ao $\mathrm{Ca}$ possuir antagonismo a outros cátions como o $\mathrm{K}$, por exemplo, podendo verificar que conforme aumentou a quantidade de $\mathrm{K}$ absorvido, reduziu-se a absorção do $\mathrm{Ca}$ (Figura 3 ). MATOS et al. (2013 b) aplicaram percolado de Resíduo Sólido Urbano (RSU) em Capim Tifton 85, e constataram que as plantas que receberam o percolado de RSU apresentaram concentrações de cálcio superiores às obtidas por aquelas que receberam apenas água da rede de abastecimento.

Os ajustes de absorção de fósforo $(P)$ em $\mathrm{g} \mathrm{kg}^{-1}$ de MS de capim Aruana, em função das lâminas de vinhaça aplicadas, ajustada conforme a equação de regressão y $=-0,0094 x+3,4681\left(R^{2}=0,6839\right)$ sendo y a absorção de $P$ em g Kg ${ }^{-1}$ e $x$ a lâmina de vinhaça aplicada, com $p \leq 0,01$ pelo teste $F$ e para os termos da equação pelo teste $T$ estão representados na figura 4. 


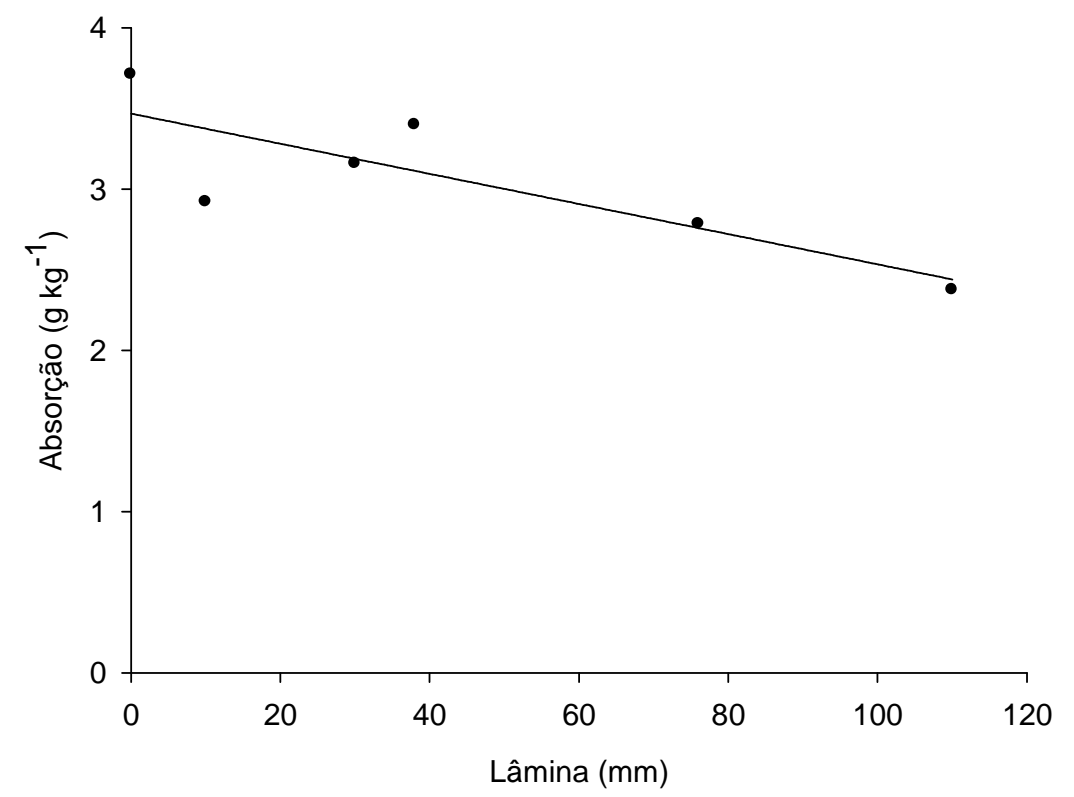

FIGURA 4. Absorção de fósforo pelo capim Aruana em função dos níveis de vinhaça aplicada.

Os valores acumulados de $\mathrm{P}$ foram 3,47 e $2,34 \mathrm{~g} \mathrm{~kg}^{-1}$, respectivamente 22,3 e $8,06 \mathrm{Kg} \mathrm{ha}^{-1}$, diferença de $32,57 \%$ entre a testemunha e a lâmina máxima de vinhaça aplicada. Já BRAZ et al. (2004) observou o acúmulo máximo de $16 \mathrm{Kg} \mathrm{ha}^{-1} \mathrm{de} \mathrm{P}$ para o capim-Mombaça entre 71 e 77 dias, valor este menor que o encontrado no presente trabalho para a lâmina máxima aplicada.

Resultados distintos foram encontrados por COSTA et al. (2008) que avaliando a quantidade de $\mathrm{P}$ extraído pelo capim-Xaraés, após aplicação conjunta de doses de $\mathrm{K}$ e N , verificaram que a extração de $\mathrm{P}$ em relação à testemunha aumentou 97,4\%. No trabalho de NAZÁRO et al. (2014) que observaram que com o aumento das taxas de aplicação de esgoto doméstico (ED) nas forrageiras Marandú, Tifton 85 e Pojuca, houve um efeito linear no acúmulo de fósforo, atingindo valor máximo com a taxa de ED de 37,67 $\mathrm{kg} \mathrm{ha}^{-1} \mathrm{dia}^{-1}$, ainda o acúmulo de fósforo nas plantas, com a menor taxa de ED foi maior que $15 \mathrm{~kg} \mathrm{ha}^{-1}$, segundo os autores esta taxa de aplicação já atenderia a demanda de fósforo das forrageiras. Essas diferenças de absorção de $P$ pelas culturas são comuns, assim como a diferença de exigência nutricional das mesmas, além de que nem todo P que se encontra no solo está disponível as plantas.

Outra justificava para tais valores pode estar relacionada com o teor de magnésio presente no solo, uma vez que $\mathrm{Mg}$ e $\mathrm{P}$ possuem relação sinérgica, ou seja, a presença do $\mathrm{Mg}$ no solo favorece a absorção de $\mathrm{P}$, e como pode ser verificado na Tabela 1 o teor de Mg no solo é relativamente baixo, contudo mesmo o solo possuindo um baixo teor de $\mathrm{P}$ a vinhaça possuía um valor elevado, logo o fato da não absorção do $P$ pelas plantas, sendo este um elemento altamente móvel nas plantas, pode estar relacionado ao fato de que a absorção de $\mathrm{P}$ pela planta, mesmo sendo um processo ativo, é necessário que, a concentração de $\mathrm{P}$ seja maior nas células radiculares do que na solução externa. 
Já a não significância do $\mathrm{Mg}$ pode estar relacionada com a sua baixa absorção diante de altas concentrações de outros cátions presente na vinhaça como o $\mathrm{Ca}$ e K. Entretanto MATOS et al. (2013 b) observaram tendência de aumento nas concentrações de $\mathrm{N}, \mathrm{K}, \mathrm{Na}, \mathrm{Ca}, \mathrm{Mg}$, na parte aérea do capim Tifton $85 \mathrm{com}$ as taxas de aplicação do percolado de Resíduo Sólido Urbano (RSU). Estes mesmo autores observaram que o capim-Tifton 85 apresentou maior concentração de potássio que cálcio e magnésio, em vista de sua grande disponibilidade no percolado de RSU.

As quantidades de $\mathrm{N}$ que foram acumuladas pelo capim, não apresentaram ajuste significativo em função das lâminas de vinhaça aplicadas, no entanto foi expressivo, na ordem de 19,17 $\mathrm{g} \mathrm{Kg}^{-1}\left(137,58 \mathrm{Kg} \mathrm{ha}^{-1}\right)$ com coeficiente de variação de 3,3\%, BRAZ et al. (2004) encontraram um acúmulo máximo de $180 \mathrm{Kg} \mathrm{ha}^{-1}$ para 0 capim-Mombaça. NAZÁRO et al. (2014) estudaram o efeito de Esgoto Doméstico (ED) em forrageiras Marandú, Tifton 85 e Pojuca notaram o efeito linear da extração de nitrogênio com o aumento das taxas de aplicação de ED, para ambos os cortes.

As quantidades de $S$ que foram acumuladas pelo capim, não apresentaram ajuste significativo em função das lâminas de vinhaça aplicadas e o valor médio das observações foi $2,77 \mathrm{~g} \mathrm{~kg}^{-1}$ com coeficiente de variação de $31,44 \%$. Por unidade de área o acumulo de enxofre foi respectivamente 17,86 e $22,20 \mathrm{Kg} \mathrm{ha}^{-1}$ para o tratamento testemunha e para a maior produtividade de MS respectivamente, diferindo de GARCIA et al. (2015) que observaram que a extração dos macronutrientes como nitrogênio, cálcio, magnésio, potássio, enxofre e fósforo em Tifton 85 e no capim Marandú aumentaram com o incremento das doses de nitrogênio aplicadas por meio do efluente doméstico tratado.

\section{CONCLUSÕES}

A pastagem do capim Aruana fertirrigada com vinhaça de cana de açúcar, atingiu uma produtividade máxima de $8,00 \mathrm{mg} \mathrm{ha}^{-1}$ para uma lâmina ótima de 44,38 mm, aplicada nas quatro primeiras semanas após o corte de uniformização;

$\checkmark \quad$ O potássio foi o nutriente extraído em maior quantidade pelas plantas conforme o aumento das doses;

$\checkmark \quad \mathrm{O}$ acúmulo de $\mathrm{Ca}, \mathrm{K}, \mathrm{P}$ apresentou ajuste significativo com as doses de vinhaça, entretanto o acúmulo de magnésio, nitrogênio e enxofre na parte aérea do capim Aruana, não apresentaram ajuste significativo.

\section{REFERÊNCIAS}

BASSO, C. J; SANTI, A. L; LAMEGO, F. P; SOMAVILLA, L; BRIGO, T. J. Vinhaça como fonte de potássio: resposta da sucessão aveia-preta/milho silagem/ milho safrinha e alterações químicas do solo na Região Noroeste do Rio Grande do Sul. Ciência Rural, Santa Maria, v.43, n.4, p. 596-602, 2013.

BRAZ, A. J. B. P.; SILVEIRA, P. M.; KLIEMANN, H. J.; ZIMMERMANN, F. J. P. Acumulação de nutrientes em folhas de milheto e dos capins braquiária e mombaça.

Pesquisa Agropecuária Tropical, Goiânia, v. 34, n. 2, p. 83-87, 2004. 
CABRAL, J. R.; FREITAS, P. S. L.; REZENDE, R.; MUNIZ, A. S.; BERTONHA, A. Impacto da água residuária de suinocultura no solo e na produção de capim-elefante. Revista Brasileira de Engenharia Agrícola e Ambiental, Campina Grande, v. 15, n. 8, p. 823-831, 2011.

CECATO, U.; RÊGO, F. C. A.; CANTO, M. W.; RIBAS, N. P.; ALMEIDA JUNIOR, J.; PETERNELLI, M. Conteúdo de minerais do capim-Tanzânia manejado em diferentes alturas, sob pastejo. In: REUNIÃO ANUAL DA SOCIEDADE BRASILEIRA DE ZOOTECNIA, 38., 2001, Piracicaba. Anais...Piracicaba: Sociedade Brasileira de Zootecnia, 2001. p.120-121.

COSTA, K. A. P.; ARAUJO, J. L.; FAQUIN,V.; OLIVEIRA, I. P.; FIGUEREIDO, F. C; GOMES, K. W. Extração de macronutrientes pela fitomassa do capim-xaraés "xaraés" em função de doses de nitrogênio e potássio. Ciência Rural, Santa Maria, v. 38, n. 4, p. 1162-1166, 2008.

FARIA, E. F. S. Formação e manejo de Pastagens (Plantas Forrageiras). Universidade Federal da Bahia. Departamento de Produção Animal Especialização em Produção de Bovinos. p. 28, 2007.

FONSECA, A. F. Disponibilidade de nitrogênio, alterações nas características químicas do solo e do milho pela aplicação de efluente de esgoto tratado. 2001. 110p. Universidade de São Paulo - Escola Superior de Agricultura Luiz de Queiroz, Piracicaba, Tese de Mestrado, 2001.

GARCIA, G. O.; RIGGO, M. M.; CECÍLIO, R. A.; REIS, E. F.; BERTOSSI, A. P. Massa seca e extração de nutrientes por duas forrageiras fertirrigadas com esgoto doméstico tratado. Bioscience Journal, Uberlândia, v. 31, n. 1; p. 215-226. 2015.

KUMMER, A. C. B.; SILVA, I. P. de FREITAS; LOBO, T. F.; GRASSI FILHO, H. Qualidade da água residuária para irrigação de trigo. Irriga, Botucatu, edição especial, p.297-308. 2012.

MARTINS, Y. A. M.; BARBOSA, K. P.; SILVA, P. C.; COSTA, R. A.; COSTA, A. R. Aplicação de diferentes doses de vinhaça sob o desenvolvimento vegetativo de plantas de milho. Enciclopédia Biosfera, Goiânia, v. 9, n.16; p. 277-284, 2013.

MATOS, A. T.; GARIGLIO, H. A. A.; LO MONACO, P. A. V. Deslocamento miscível de cátions provenientes da vinhaça em colunas de solo. Revista Brasileira de Engenharia Agrícola e Ambiental, Campina Grande, v. 17, n. 7, 2013 a.

MATOS, A. T.; SILVA, D.F.; LO MONACO, P. A. V.; PEREIRA, O.G. Produtividade e composição química do capim-Tifton 85 submetido a diferentes taxas de aplicação do percolado de resíduo sólido urbano. Engenharia Agrícola, Jaboticabal, v. 33, n. 1, 2013 b. 
NAZÁRIO, A. A.; GARCIA, G. O.; REIS, E. F.; MENDONÇA, E. S. MELLINE, J. G. B. Acúmulo de nutrientes por forrageiras cultivadas em sistema de escoamento superficial para tratamento de esgoto doméstico. Revista Ambiente \& Água, Taubaté, v. 9, n. 1, 2014.

PAULINO, J.; ZOLIN, C. A.; BERTONHA, A.; FREITAS, P. S.L.; FOLEGATTI, M. V. Estudo exploratório do uso da vinhaça ao longo do tempo. II. Características da canade-açúcar. Revista Brasileira Engenharia Agrícola e Ambiental, Campina Grande, v. 15, n. 3, p. 244-249, 2011.

SANTOS JR., J. D. G. Fertilidade do solo no acúmulo de forragem e nutrição do capim-Tanzânia sob pastejo na região dos Cerrados. 2005. 105f. Tese (Doutorado em Solos e Nutrição de Plantas) - Escola Superior de Agricultura "Luiz de Queiroz", Piracicaba.

SILVA, J. G. D.; MATOS, A. T.; BORGES, A. C.; PREVIERO, C. A. Composição químico-bromatológica e produtividade do capim-mombaça cultivado em diferentes lâminas de efluente do tratamento primário de esgoto sanitário. Revista Ceres, Viçosa, v. 59 , n.5, p. 606-613, 2012.

SILVA, P. C.; COSTA, R. A.; GIONGO, P. R.; MORAES, M. H.; LANA, R. M. Aplicação de doses de vinhaça sob desenvolvimento vegetativo de pastagem degradada e propriedades físicas do solo. Enciclopédia Biosfera, Goiânia, v. 9, n. 17; p.233-246, 2013.

SILVA, A. P. M.; BONO, J. A. M.; PEREIRA, F. A. R. Aplicação de vinhaça na cultura da cana-de-açúcar: Efeito no solo e na produtividade de colmos. Revista Brasileira de Engenharia Agrícola e Ambiental, Campina Grande , v. 18, n. 1, p.38-43, 2014.

SOUZA, J. A. A; BATISTA, R. O; RAMOS, M. M; SOARES, A. A. Alterações nas características físicas do solo decorrentes da aplicação de esgoto doméstico tratado. Acta Scientiarum Technology, Maringá, v. 32, n. 4, p. 361-366, 2010.

UFV - UNIVERSIDADE FEDERAL DE VIÇOSA. SAEG - Sistema de análises estatísticas e genéticas. Versão 4.0. Viçosa, MG, 150 p, 1997. (Manual do usuário).

ZOLIN, C. A.; PAULINO, J.; BERTONHA, A.; FREITAS, P. S. L.; FOLEGATTI, M. V. Estudo exploratório do uso da vinhaça ao longo do tempo. II. Características do Solo. Revista Brasileira Engenharia Agrícola e Ambiental, Campina Grande cidade, v. 15, n. 3, p. 22-28, 2011. 